\title{
BMJ Open Preadmission glucocorticoid use and anastomotic leakage after colon and rectal cancer resections: a Danish cohort study
}

Eva Bjerre Ostenfeld, ${ }^{1,2}$ Rune Erichsen, ${ }^{1}$ John A Baron, ${ }^{1,3}$ Ole Thorlacius-Ussing, ${ }^{2}$ Lene Hjerrild Iversen, ${ }^{4}$ Anders H Riis, ${ }^{1}$ Henrik Toft Sørensen, ${ }^{1}$ on behalf of the Danish Colorectal Cancer Group

To cite: Ostenfeld $\mathrm{EB}$, Erichsen R, Baron JA, et al. Preadmission glucocorticoid use and anastomotic leakage after colon and rectal cancer resections: a Danish cohort study. BMJ Open 2015;5: e008045. doi:10.1136/ bmjopen-2015-008045

- Prepublication history and additional material is available. To view please visit the journal (http://dx.doi.org/ 10.1136/bmjopen-2015008045).

Received 24 February 2015 Revised 23 July 2015 Accepted 21 August 2015

\section{CrossMark}

${ }^{1}$ Department of Clinical Epidemiology, Aarhus University Hospital, Aarhus, Denmark

${ }^{2}$ Department of

Gastrointestinal Surgery, Aalborg University Hospital, Aalborg, Denmark

${ }^{3}$ Department of Medicine, University of North Carolina, School of Medicine, Chapel Hill, North Carolina, USA

${ }^{4}$ Department of Surgery, Aarhus University Hospital, Aarhus, Denmark

Correspondence to Dr Eva Bjerre Ostenfeld; evaosten@rm.dk

\section{ABSTRACT}

Objective: To examine whether preadmission glucocorticoid use increases the risk of anastomotic leakage after colon and rectal cancer resections.

Design: A population-based cohort study.

Setting: Denmark (2001-2011).

Participants: We identified patients who had undergone a primary anastomosis after a colorectal cancer resection by linking medical registries.

Participants who filled their most recent glucocorticoid prescription $\leq 90,91-365$ and $>365$ days before their surgery date were categorised as current, recent and former users, respectively.

Main outcome measures: We calculated 30-day absolute risk of anastomotic leakage and computed ORs using logistic regression models with adjustment for potential confounders.

Results: Of the 18190 patients with colon cancer, anastomotic leakage occurred in 1184 (6.5\%). Glucocorticoid use overall was not associated with an increased risk of leakage (6.4\% vs $6.9 \%$ among neverusers; OR $1.05 ; 95 \% \mathrm{Cl} 0.89$ to 1.23 ). Categories of oral, inhaled or intestinal-acting glucocorticoids did not greatly affect risk of leakage. Anastomotic leakage occurred in $695(13.2 \%)$ of 5284 patients with rectal cancer. Glucocorticoid use overall slightly increased risk of leakage (14.6\% vs $12.8 \%$ among never-users; OR $1.36,95 \% \mathrm{Cl} 1.08$ to 1.72 ). Results did not differ significantly within glucocorticoid categories.

Conclusions: Preadmission glucocorticoids modestly increased the risk of anastomotic leakage mainly after rectal cancer resection. However, absolute risk differences were small and the clinical impact of glucocorticoid use may therefore be limited.

\section{INTRODUCTION}

Anastomotic leakage is a serious complication after colorectal cancer (CRC) resection, and inevitably increases morbidity, mortality and hospital resource utilisation. ${ }^{1}{ }^{2}$ Moreover, leakage may negatively affect the

\section{Strengths and limitations of this study}

- The study included all Danish patients with colon and rectal cancer who had a primary anastomosis after a colorectal cancer resection during the study period. The study had complete follow-up on all participants.

- Using electronic registries, we had accurate data on glucocorticoid prescriptions.

- Because there were no clear standards for the recording of anastomotic leakage during the study period, completeness and validity in the registries may be imperfect.

- The completeness of the Danish National Registry of Patients may vary for different diseases, and we cannot exclude the possibility that confounding by indication influenced our results although we adjusted for comorbidity in multivariate models.

risk of local cancer recurrence and long-term survival. $^{3}$

Synthetic glucocorticoids are potent immunosuppressive drugs that are widely used to treat various chronic inflammatory diseases and some malignancies. ${ }^{4}$ Although glucocorticoids have been associated with impaired wound healing in skin, ${ }^{5}{ }^{6}$ their effect on colon and rectal anastomoses is controversial. ${ }^{7-18}$ Some animal studies of intestinal anastomoses have demonstrated that glucocorticoids impair healing and reduce the tensile strength of wounds, ${ }^{7-9}$ while others have not. ${ }^{10} 11$ Clinical data are also mixed. Several reports have indicated that glucocorticoid use might predispose to leakage,${ }^{12-15}$ although others have not. ${ }^{16-18}$ Unfortunately, existing studies were limited by sparse data (including 0-4 exposed cases), ${ }^{12-18}$ and by the consideration of colon and rectal surgery together rather than separately. ${ }^{12-14}{ }^{17}$ It is important to 
distinguish between colon and rectal procedures, because the anatomy and surgical techniques differ, leading to substantial differences in leakage rates: $3-4 \%$ after colonic surgery compared with $11-12 \%$ after rectal surgery. ${ }^{19}$

On the basis of available evidence, surgeons may question the safety of primary anastomoses in glucocorticoid users. To address the limitations of earlier studies, we examined associations between glucocorticoid administration and the risk of anastomotic leakage, in a large nationwide cohort of patients with colon and rectal cancer.

\section{MATERIALS AND METHODS \\ Setting}

We conducted a cohort study in the setting of the entire Danish population, comprising approximately 6.5 million individuals cumulatively over the study period. The Danish National Health Care provides free access to tax-supported health services for all residents and refunds a part of patient costs for most prescribed drugs. Health service utilisation is registered to individual patients by use of the personal identification number assigned to each Danish citizen at birth and to residents on immigration. The use of this system facilitates unambiguous individual-level linkage of nationwide registries. $^{20}$

\section{Patients with colon and rectal cancer}

We identified all 23474 residents of Denmark who had a colonic or rectal cancer resection and primary anastomosis between 1 May 2001 and 31 December 2011, and who were reported in the database of the Danish Colorectal Cancer Group ${ }^{21}$ (figure 1). Beginning in 2001, this clinical database has registered all patients with an incident colon or rectal adenocarcinoma, the latter defined as those located $15 \mathrm{~cm}$ or less from the anus, diagnosed or treated in surgical departments in Denmark. ${ }^{21}$ Completeness of cancer registration (ie, the proportion of those registered in the database out of those registered in Danish National Registry of Patients) in the database was $98-100 \%$ during $2001-2010 .^{22}$ Data regarding patient, tumour and treatment characteristics, as well as postoperative outcomes including anastomotic leakage (arbitrarily defined as those occurring within 30 days postoperatively), are collected by the Danish Colorectal Cancer Group using standardised forms that are completed by the treating physicians. ${ }^{21}$ We retrieved data regarding preoperative American Society of Anesthesiologists' Physical Status Classification (ASA) score, ${ }^{23}$ cancer site, tumour extent, node involvement and distant metastases allowing for staging (recorded as localised or non-localised if the cancer involved nodes or distant organs $)^{24}$ as well as date of surgery, surgical urgency (planned or acute), approach (laparoscopy or laparotomy), procedure (type of resection), perioperative blood transfusion and postoperative anastomotic leakage. Finally, we obtained information regarding smoking status, which is recorded from patient questionnaires collected by the Danish Colorectal Cancer Group until 2009, and thereafter by the treating physicians.

\section{Use of glucocorticoids}

The Danish National Registry of Medicinal Products has automatically recorded prescriptions dispensed at Danish pharmacies with complete coverage since $1995{ }^{25}$ Each record logs information about the type and quantity of medication dispensed according to the Anatomical Therapeutic Chemical (ATC) Classification System and the prescription redemption date. We used this registry to identify all prescriptions of oral, inhaled and intestinal-acting glucocorticoids redeemed before the
Figure 1 Flow chart illustrating exclusions of patients with colorectal cancer recorded in the Danish Colorectal Cancer Database (DCCD), 2001-2011.

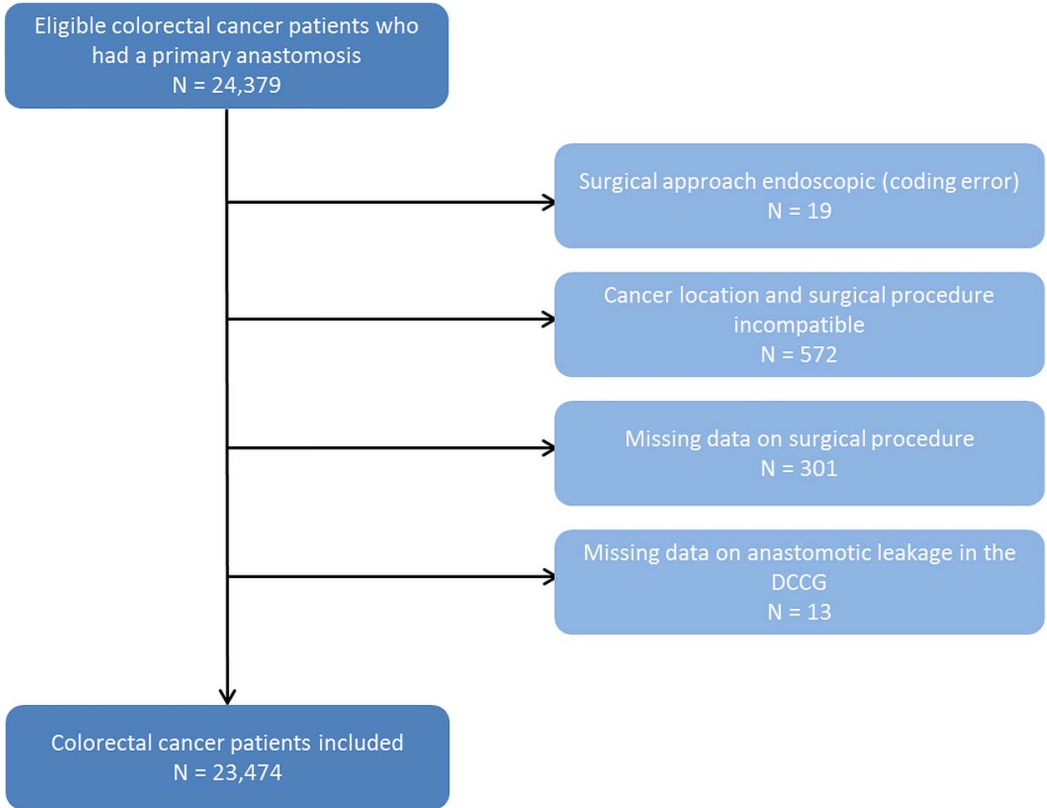


CRC surgery date (see online supplementary table S1 for ATC codes). Intestinal-acting glucocorticoids included rectally administered formulas as well as capsules that release active substances into the ileum or proximal colon. On the basis of methods used previously, ${ }^{26}$ we categorised exposure into the following five main groups: (1) lack of use ('never-use'), (2) oral glucocorticoid use only, (3) inhaled glucocorticoid use only, (4) intestinal-acting glucocorticoid use only and (5) mixed use (ie, treatment with glucocorticoids from at least two of the previous three groups). We further categorised oral and inhaled glucocorticoid use according to the timing of use as: current use (most recent prescription filled within 90 days before the surgery date), recent use (most recent prescription filled within 91365 days before the surgery date) and former use (most recent prescription filled more than 365 days before the surgery date). Intestinal-acting glucocorticoid use was not divided into subcategories owing to the paucity of individuals in that group.

\section{Comorbidity and medication}

The Danish National Registry of Patients has tracked all non-psychiatric hospitalisations since 1977, and outpatient visits since 1995, including essentially all specialist care in the country. ${ }^{27}$ Recorded information includes dates of admission and discharge, surgical and diagnostic procedures, and discharge diagnoses coded by physicians according to the 8th revision of the International Classification of Diseases (ICD-8) until the end of 1993 and the 10th revision (ICD-10) since then. Using records from the Danish National Registry of Patients and the Charlson Comorbidity Index (CCI), we summarised each patient's medical history from 1977 until the surgery date, excluding colon or rectal cancer diagnosis (see online supplementary table S2 for ICD codes defining a modified CCI) ${ }^{28}$ The CCI assigns between 1 and 6 points to a range of diseases, which are then summed to obtain an aggregate score. We grouped patients according to their CCI score: 0 (low comorbidity), 1-2 (moderate comorbidity) and $3+$ (severe comorbidity). In addition, we obtained recorded diagnoses of inflammatory bowel disease, autoimmune disease, alcoholism and obesity, because these diagnoses are not included in the CCI (see online supplementary table S3 for ICD codes).

Using the Danish National Registry of Medicinal Products, we also identified filled prescriptions of nonsteroidal anti-inflammatory drugs, medications for chronic obstructive pulmonary disease (COPD) other than glucocorticoids, and immunosuppressants (see online supplementary table S4 for ATC codes).

\section{Patients with anastomotic leakage after colon or rectal cancer resection}

We identified patients with anastomotic leakage recorded in the Danish Colorectal Cancer Group database or in the Danish National Registry of Patients, using the ICD codes associated with anastomotic leakage or surgery codes for surgical repair of anastomotic leakage (see online supplementary table S5 for ICD-10 codes). Recording of anastomotic leakage in the database is typically based on clinically evident leakage, which, at the discretion of the surgeon, is confirmed by contrast barium enema, CT or surgery.

\section{Statistical analysis}

We analysed patients with colon and rectal cancer separately. We tabulated the frequencies of glucocorticoid use with regard to the characteristics of the patient, the tumour and the surgery, including $\mathrm{p}$ values, by using Pearson's $\chi^{2}$ test. According to our predefined glucocorticoid exposure groups, we estimated absolute risk of anastomotic leakage within 30 days postoperatively and 95\% CIs using Jeffreys' method. ${ }^{29}$ Corresponding risk differences were calculated subtracting the estimate for never-use from those for glucocorticoid users. We computed ORs as a measure of relative risk and 95\% CIs associating anastomotic leakage after colon or rectal cancer surgery with glucocorticoid exposure in crude and adjusted logistic regression models. On the basis of their associations with both anastomotic leakage risk and glucocorticoid use, we included the following covariates in the model as potential confounders: sex, age, CCI score, ASA score $(\leq 2,>2$, unknown), history of inflammatory bowel disease, alcoholism/use of disulfiram (single variable) and smoking status at the time of the surgery (current, former, never or unknown), with medications for COPD as its proxy, as well as prescriptions for non-aspirin non-steroidal anti-inflammatory drugs filled within 90 days before the surgery date. ${ }^{30} 31$ Missing data (eg, for smoking) were categorised separately and included in the analysis (see tables 1 and 2 for a description of categories within each covariate). To examine variations in postoperative anastomotic leakage, ORs were calculated within subgroups of sex, age, year of surgery, cancer site, cancer stage, CCI score, ASA score and smoking status, as well as surgical urgency and approach, type of procedure and perioperative blood transfusion.

In sensitivity analyses, we first changed the time window for filled glucocorticoid prescriptions to 60 and 120 days before the surgery dates. Second, because there are no clear standards for the recording of anastomotic leakage, we restricted anastomotic leakage to patients who were re-operated on, to heighten the predictive value of our outcome. Leakages that were treated only by non-surgical drainage, for example, ultrasonic, were not included in this analysis.

Statistical analyses were performed using Stata V.12.0 (StataCorp LP, College Station, Texas, USA) and SAS V.9.2 (SAS Institute Inc, Cary, North Carolina, USA).

\section{RESULTS}

Patients with colon cancer

We identified 18190 patients with colon cancer who had a primary anastomosis after tumour resection during 
Table 1 Characteristics of patients who underwent resection for colon cancer, by use of any glucocorticoids, Denmark, 2001-2011

\begin{tabular}{|c|c|c|c|}
\hline \multirow[b]{2}{*}{ Characteristics } & \multicolumn{2}{|l|}{ Colon cancer } & \multirow[b]{2}{*}{ p Value } \\
\hline & $\begin{array}{l}\text { No glucocorticoid } \\
\text { use, } \mathrm{N}=14041 \\
\mathrm{n}(\%)\end{array}$ & $\begin{array}{l}\text { Glucocorticoid } \\
\text { use, } N=4149 \\
\text { n (\%) }\end{array}$ & \\
\hline Sex & & & 0.000 \\
\hline Female & $7122(50.7)$ & 2369 (57.1) & \\
\hline Male & 6919 (49.3) & 1780 (42.9) & \\
\hline Age, years & & & 0.000 \\
\hline$<60$ & $2399(17.1)$ & $482(11.6)$ & \\
\hline $60-69$ & $3841(27.4)$ & 949 (22.9) & \\
\hline $70-79$ & $4688(33.4)$ & $1582(38.1)$ & \\
\hline $80+$ & $3113(21.2)$ & $1136(27.4)$ & \\
\hline Year of resection & & & 0.000 \\
\hline 2001-2004 & 4767 (34.0) & 1074 (25.9) & \\
\hline $2005-2008$ & 5327 (37.9) & 1642 (39.6) & \\
\hline 2009-2011 & $3947(28.1)$ & $1433(34.5)$ & \\
\hline Stage & & & 0.001 \\
\hline Localised & 7192 (51.2) & $2261(54.5)$ & \\
\hline Non-localised & $6510(46.4)$ & $1785(43.0)$ & \\
\hline Unknown & $339(2.4)$ & $103(2.5)$ & \\
\hline $\mathrm{CCl}$ score & & & 0.001 \\
\hline 0 & 8557 (60.9) & 1448 (34.9) & \\
\hline $1-2$ & 4074 (29.0) & $1812(43.7)$ & \\
\hline $3+$ & $1410(10.0)$ & 889 (21.4) & \\
\hline ASA score & & & 0.000 \\
\hline$\leq 2$ & $10616(75.6)$ & 2575 (62.1) & \\
\hline$>2$ & $2812(20.0)$ & $1420(34.2)$ & \\
\hline Unknown & $613(4.4)$ & $154(3.7)$ & \\
\hline IBD & $91(0.7)$ & $108(2.6)$ & 0.000 \\
\hline $\begin{array}{l}\text { Autoimmune disorders or immunosuppressive drug } \\
\text { use }\end{array}$ & $90(0.6)$ & $256(6.2)$ & 0.000 \\
\hline Obesity & 405 (2.9) & $208(5.0)$ & 0.000 \\
\hline Alcoholism & $488(3.5)$ & $159(3.8)$ & 0.276 \\
\hline Tobacco use & & & 0.000 \\
\hline Current use & $2088(14.9)$ & $563(13.6)$ & \\
\hline Former use & $4159(29.6)$ & $1429(34.4)$ & \\
\hline Never use & $3569(25.4)$ & $898(21.6)$ & \\
\hline Unknown & $4225(30.1)$ & $1259(30.3)$ & \\
\hline NSAIDs & $3337(23.8)$ & $1180(28.4)$ & 0.000 \\
\hline COPD medications & $1547(11.0)$ & $2404(57.9)$ & 0.000 \\
\hline Surgical urgency & & & 0.190 \\
\hline Planned & $12140(86.5)$ & 3617 (87.2) & \\
\hline Acute & $1894(13.5)$ & $532(12.8)$ & \\
\hline Unknown & $7(0.1)$ & $0(0.0)$ & \\
\hline Surgical approach & & & 0.004 \\
\hline Laparoscopy & 3446 (24.5) & $1111(26.8)$ & \\
\hline Laparotomy & $10595(75.5)$ & 3038 (73.2) & \\
\hline Surgical procedure & & & 0.000 \\
\hline Ileocaecal resection & $45(0.3)$ & $8(0.2)$ & \\
\hline Right-sided hemicolectomy & $6925(49.3)$ & $2239(54.0)$ & \\
\hline Transverse colon resection & $356(2.5)$ & $101(2.4)$ & \\
\hline Left-sided hemicolectomy & $1546(11.0)$ & $447(10.8)$ & \\
\hline Sigmoid colon resection & $4791(34.1)$ & $1238(29.8)$ & \\
\hline Other resections & $15(0.1)$ & $8(0.2)$ & \\
\hline Colectomy and IRA & $363(2.6)$ & $108(2.6)$ & \\
\hline Rectal resection & - & - & \\
\hline Perioperative blood transfusion & & & 0.000 \\
\hline Yes & 3312 (23.6) & $1120(27.0)$ & \\
\hline No & $10611(75.6)$ & 2999 (72.3) & \\
\hline Missing/unknown & $118(0.8)$ & $30(0.7)$ & \\
\hline
\end{tabular}


Table 2 Characteristics of patients who underwent resection for rectal cancer, by use of any glucocorticoids, Denmark, 2001-2011

\begin{tabular}{|c|c|c|c|}
\hline \multirow[b]{2}{*}{ Characteristics } & \multicolumn{2}{|l|}{ Rectal cancer } & \multirow[b]{2}{*}{$p$ Value } \\
\hline & $\begin{array}{l}\text { No glucocorticoid } \\
\text { use, } \mathrm{N}=4317 \\
\mathrm{n}(\%)\end{array}$ & $\begin{array}{l}\text { Glucocorticoid } \\
\text { use, } N=967 \\
\text { n (\%) }\end{array}$ & \\
\hline Sex & & & 0.000 \\
\hline Female & 1737 (40.2) & 463 (47.9) & \\
\hline Male & $2580(59.8)$ & 504 (52.1) & \\
\hline Age, years & & & 0.000 \\
\hline$<60$ & $1187(27.5)$ & 224 (23.3) & \\
\hline 60-69 & 1617 (37.5) & 321 (33.2) & \\
\hline $70-79$ & $1152(26.7)$ & 326 (33.7) & \\
\hline $80+$ & $361(8.4)$ & $96(9.9)$ & \\
\hline Year of resection & & & 0.004 \\
\hline 2001-2004 & 1418 (32.9) & $272(28.1)$ & \\
\hline $2005-2008$ & 1651 (38.2) & $372(38.5)$ & \\
\hline 2009-2011 & $1248(28.9)$ & 323 (33.4) & \\
\hline Stage & & & 0.866 \\
\hline Localised & $2460(57.0)$ & 557 (57.6) & \\
\hline Non-localised & 1775 (41.1) & $390(40.3)$ & \\
\hline Unknown & $82(1.9)$ & $20(2.1)$ & \\
\hline $\mathrm{CCl}$ score & & & 0.000 \\
\hline 0 & 3131 (72.5) & $490(50.7)$ & \\
\hline $1-2$ & 970 (22.5) & 355 (36.7) & \\
\hline $3+$ & $216(5.0)$ & $122(12.6)$ & \\
\hline ASA score & & & 0.000 \\
\hline$\leq 2$ & 3827 (88.3) & 766 (79.9) & \\
\hline$>2$ & $432(10.0)$ & $181(18.7)$ & \\
\hline Unknown & $77(1.8)$ & $23(2.4)$ & \\
\hline IBD & $25(0.6)$ & $6(0.8)$ & 0.879 \\
\hline $\begin{array}{l}\text { Autoimmune disorders or immunosuppressive drug } \\
\text { use }\end{array}$ & $26(0.6)$ & $50(5.2)$ & 0.000 \\
\hline Obesity & $77(1.8)$ & $29(3.0)$ & 0.015 \\
\hline Alcoholism & $160(3.7)$ & $34(3.5)$ & 0.776 \\
\hline Tobacco use & & & 0.718 \\
\hline Current use & $819(19.0)$ & $182(18.8)$ & \\
\hline Former use & $1529(35.4)$ & $359(37.1)$ & \\
\hline Never use & $1155(26.8)$ & $244(25.2)$ & \\
\hline Unknown & $814(18.9)$ & $182(18.8)$ & \\
\hline NSAIDs & $806(18.7)$ & $222(23.0)$ & 0.002 \\
\hline COPD medications & $403(9.3)$ & $550(56.9)$ & 0.000 \\
\hline Surgical urgency & & & 0.700 \\
\hline Planned & 4295 (99.5) & $963(99.6)$ & \\
\hline Acute & $22(0.5)$ & $4(0.4)$ & \\
\hline Unknown & $7(0.1)$ & $0(0.0)$ & \\
\hline Surgical approach & & & 0.141 \\
\hline Laparoscopy & $972(22.5)$ & $239(24.7)$ & \\
\hline Laparotomy & $3345(77.5)$ & 728 (75.3) & \\
\hline Surgical procedure & & & \\
\hline Rectal resection & $4317(100.0)$ & $967(100.0)$ & \\
\hline Perioperative blood transfusion & & & 0.907 \\
\hline Yes & $830(19.2)$ & $189(19.5)$ & \\
\hline No & 3465 (80.3) & $774(80.0)$ & \\
\hline Missing/unknown & $22(0.5)$ & $4(0.4)$ & \\
\hline
\end{tabular}

2001-2011. We found that 2170 study participants $(11.9 \%)$ had at least one prescription for glucocorticoids within 1 year before their surgery date (table 1 ).
Glucocorticoid users were more likely than never-users to be female and elderly (median age 74 vs 71 years). Compared with never-users, severe comorbidity and a 
high ASA score were almost twice as prevalent among glucocorticoid users, although $34.9 \%$ of users had a CCI score of 0 . Prescriptions for non-steroidal antiinflammatory drugs and COPD agents were also more prevalent among these patients.

Anastomotic leakage occurred in 1184 patients with colon cancer $(6.5 \%)$. Glucocorticoid users contributed 287 cases $(24.2 \%)$, yielding an overall absolute risk of leakage of $6.9 \%$ vs $6.4 \%$ among never-users (table 3 ). Absolute risk did not differ substantially among subgroups of users of oral, inhaled, intestinal-acting or mixed glucocorticoids.

Compared with never-users, glucocorticoid use overall was not associated with an increased relative risk of anastomotic leakage (table 3). Although not statistically significant, risk was slightly increased among current (adjusted OR (aOR) $=1.24 ; 95 \%$ CI 0.82 to 1.88 ) and recent $(\mathrm{aOR}=1.43 ; 95 \%$ CI 0.87 to 2.34 ) users of oral glucocorticoids. The relative risk estimate for use of intestinal-acting glucocorticoids was imprecise $(\mathrm{aOR}=1.47,95 \%$ CI 0.56 to 3.84$)$. We observed no association for inhaled glucocorticoids. With the exception of alcoholism $(\mathrm{aOR}=2.58$; $95 \%$ CI 1.23 to 5.39$)$, the association between glucocorticoid use and anastomotic leakage did not differ materially across strata of covariates (figure $2 \mathrm{~A}$ ).

In sensitivity analyses in which the time window for the definition of current use was changed to 60/ 120 days before surgery, results were close to those in the main analysis, using either cut-off (data not shown). When we restricted analyses to anastomotic leakages that required surgical intervention, we observed 98 (8\%) fewer outcomes. However, absolute and relative risk estimates were essentially unchanged (data not shown).

\section{Rectal cancer patients}

Of the 5284 patients with rectal cancer resected, 458 $(8.7 \%)$ used glucocorticoids within 1 year before surgery. Among patients with rectal cancer, glucocorticoid users were more likely than never-users to be female and elderly (median age 68 years vs 66 years) (table 2). Similarly, severe comorbidity, high ASA score and prescriptions of non-steroidal anti-inflammatory drugs and COPD agents were more prevalent among patients using glucocorticoids.

Anastomotic leakage occurred in 695 patients with rectal cancer $(13.2 \%)$. Overall, the absolute risk of leakage was $14.6 \%$ among glucocorticoid users versus $12.8 \%$ among never-users (table 4). Absolute risks among current, recent and former users of oral glucocorticoids were $15.9 \%, 13.0 \%$ and $16.3 \%$, respectively. Current users of inhaled glucocorticoids had the highest absolute risk (17.7\%); recent users of inhaled glucocorticoids and those using mixed glucocorticoids had the lowest risks $(11.1 \%$ and $11.7 \%$, respectively). Anastomotic leakage occurred among $16.7 \%$ of users of intestinal-acting glucocorticoids.

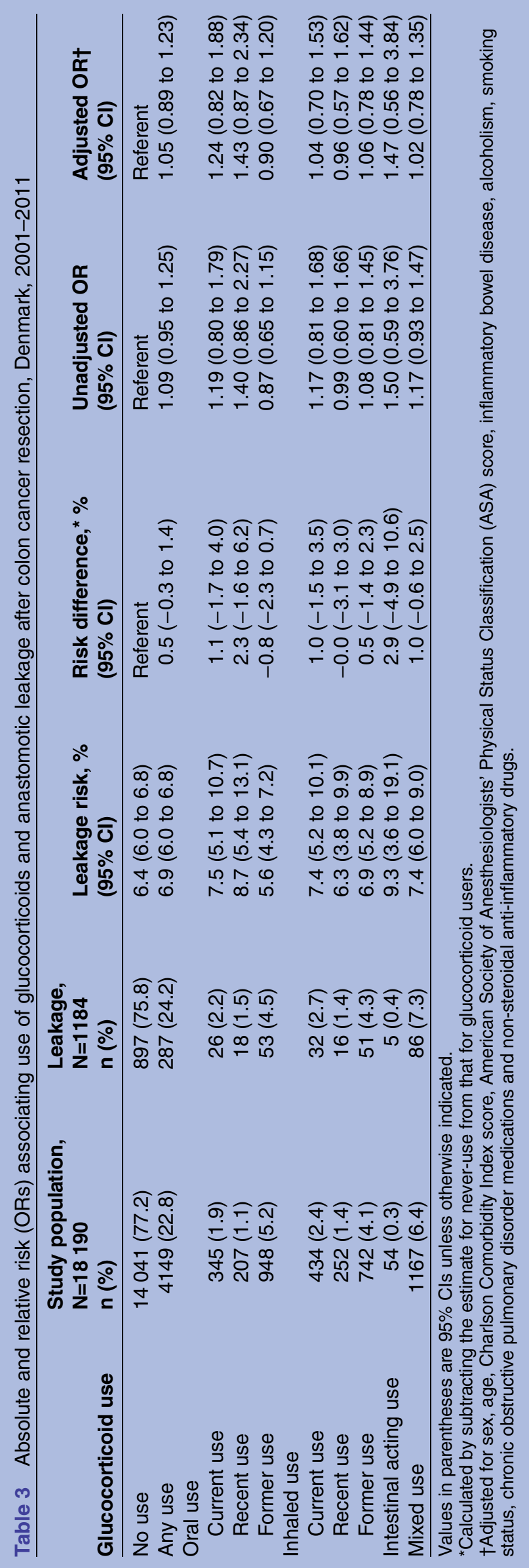


Figure 2 (A) Subgroup analysis associating glucocorticoids and anastomotic leakage following colon cancer surgery compared to never-use. (B) Subgroup analysis associating glucocorticoids and anastomotic leakage following rectal cancer surgery compared to never-use.

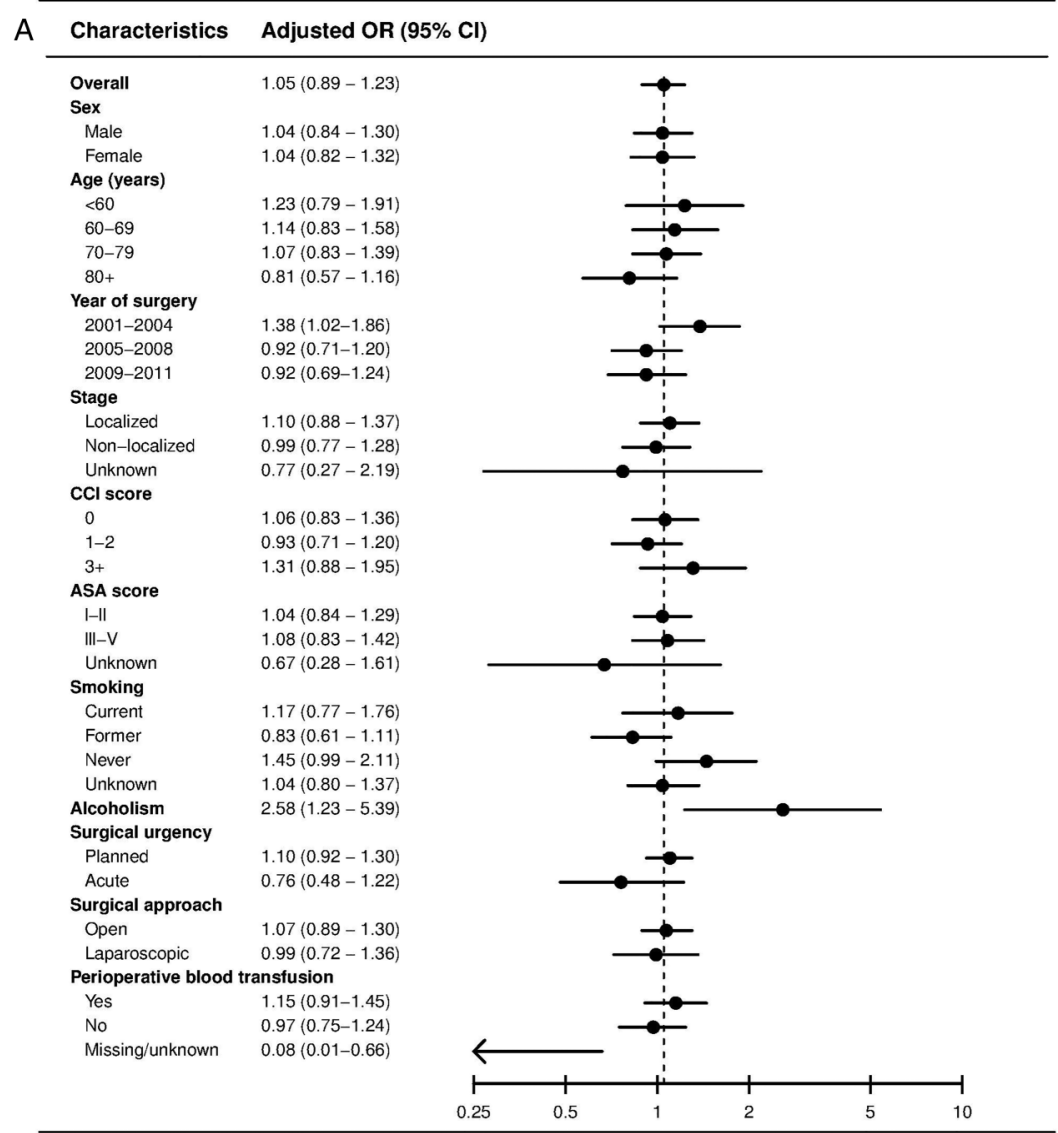

Abbreviations: OR, odds ratio; CCl, Charlson Comorbidity Index score; ASA, American Society of Anesthesiologists Physical Status Classification IRA, leorectal anastomosis. CRs achased for sem, age,

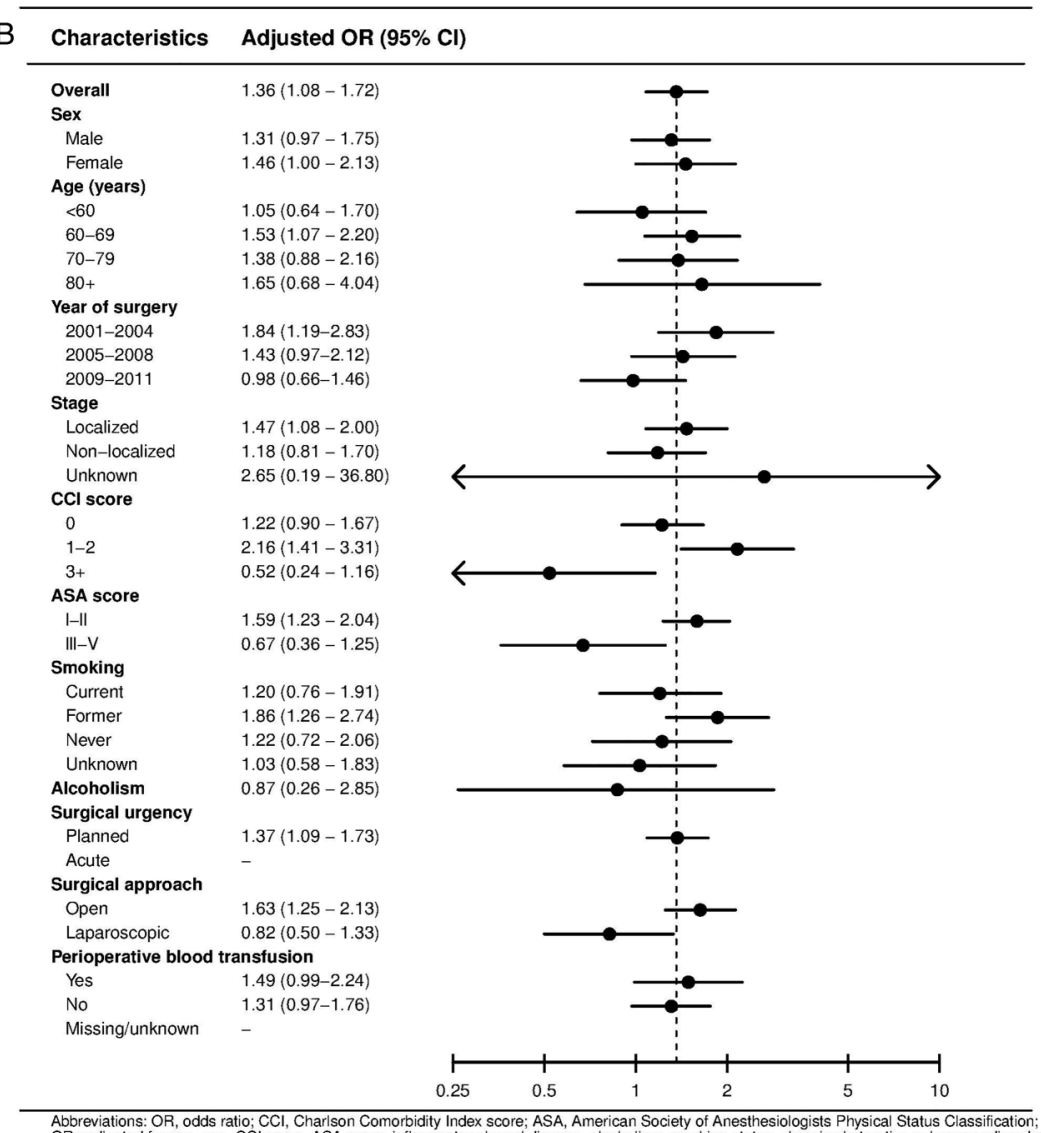

Abbreviations: OR, odds ratio; CCI, Charlson Comorbidity Index score; ASA, American Society of Anesthesiologists Physical Status Classification
ORs adiusted for sex, age, CCCl score, ASA score, inflammatory bowel disease, alcoholism, smoking status, chronic obstructive pulmonary disord medications, and non'-steroida ant-inflam scotery drugs. 


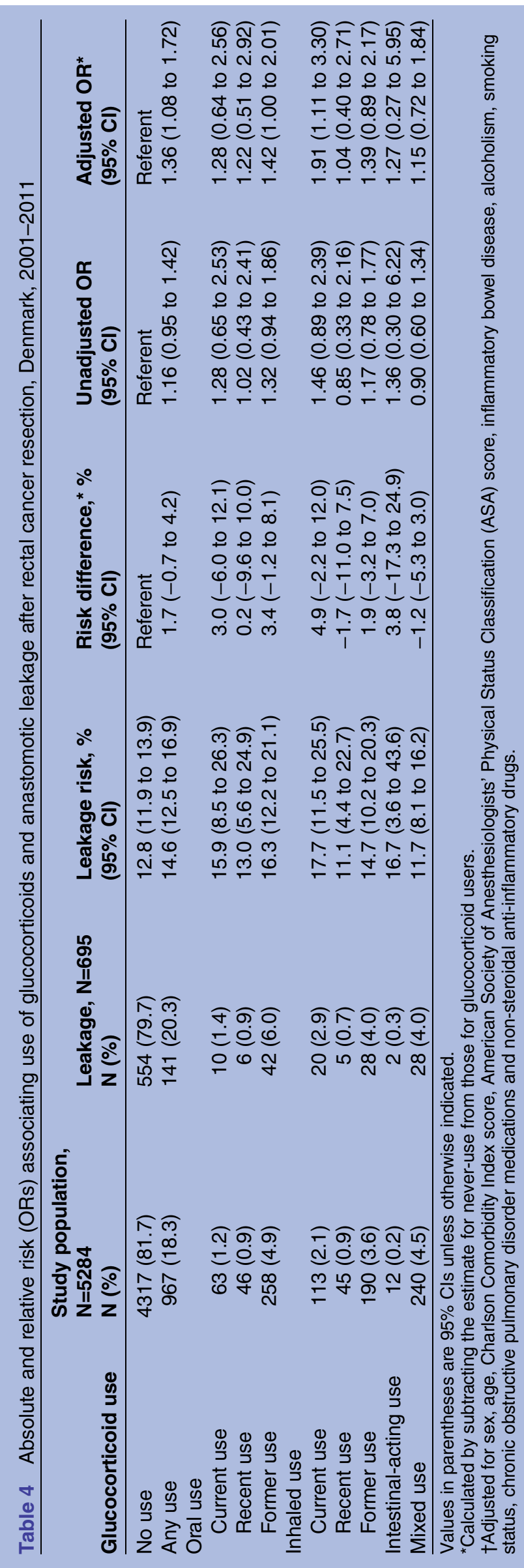

Compared with never-users, glucocorticoid use was associated with an increased risk of anastomotic leakage after rectal cancer resection $(\mathrm{aOR}=1.36 ; 95 \%$ CI 1.08 to 1.72) (table 4). Relative risks were modestly increased in all subgroups of oral glucocorticoid users (current use: $\mathrm{aOR}=1.28 ; 95 \%$ CI 0.64 to 2.56 ; recent use: $\mathrm{aOR}=1.22$; $95 \%$ CI 0.51 to 2.92 ; and former use: $\mathrm{aOR}=1.42 ; 95 \%$ CI 1.00 to 2.01). Among users of inhaled glucocorticoids, current users had the highest risk: aOR=1.91; 95\% CI 1.11 to 3.30. Estimates for the use of intestinal-acting and mixed glucocorticoids showed no strong associations. Our stratified analysis revealed no major difference across strata in the relative association between glucocorticoid use and postoperative rectal anastomotic leakage (figure 2B).

After changing the definition of current use to a 60-day window before surgery, ORs were somewhat higher for current use of oral glucocorticoids $(\mathrm{aOR}=1.63$; 95\% CI 0.77 to 3.46) and somewhat lower for recent users ( $\mathrm{aOR}=0.97 ; 95 \%$ CI 0.44 to 2.17 ). However, the $95 \%$ CIs for these estimates overlapped with those of the main analysis. Remaining estimates were virtually unchanged using either cut-off (data not shown). When we restricted analyses to anastomotic leakages that required reoperation, we observed 215 (31\%) fewer outcomes. However, results did not differ materially (data not shown).

\section{DISCUSSION}

In this nationwide population-based study, we found that current and recent users of oral glucocorticoids exhibited a non-significant modest increase in the relative risk of anastomotic leakage after colon cancer resection. Among patients with rectal cancer, relative risk increased moderately for almost any type of glucocorticoid use. For both cancers, differences in absolute risk among current and recent users versus never-users were small, and the clinical impact of their use is therefore limited.

This study extends previous research because it includes considerably more participants than previous investigations and provides detailed data on different types of glucocorticoids and the timing of their use. In addition, we analysed patients with colon and rectal cancer separately. Previous studies that examined whether glucocorticoids predict anastomotic leakage after CRC resection had inconsistent results. ${ }^{12-18}$ On the basis of 12 studies published between 1996 and 2012, a recent review provided combined rates for leakage: $6.8 \%$ (95\% CI $5.5 \%$ to $9.1 \%$ ) in 1034 patients exposed to steroids preoperatively versus $3.3 \%$ (95\% CI $2.9 \%$ to $3.6 \%$ ) in 8410 unexposed patients. ${ }^{32}$ Overall risk was higher in our cohort of patients with colon and rectal cancer. Comparison of our findings to previous studies is difficult because of differences in definitions of exposure, study populations, indications for resection and surgical procedures performed. Moreover, the lack of a standard definition of anastomotic leakage ${ }^{33}$ is likely to explain some of the disparity. 
Other major strengths of the present study include its population-based design within the setting of a taxsupported, uniformly organised healthcare system. Using electronic registries, we had accurate data on exposure and covariates. ${ }^{25} 2734$ The Danish Colorectal Cancer Group database provided a complete cohort of patients with CRC during the study period, as well as detailed information about surgical treatment and anastomotic leakage. ${ }^{22}$ However, as in all observational studies of leakage, we cannot entirely exclude the possibility of selection bias. If surgeons are more reluctant to create a primary anastomosis in glucocorticoid users than in never-users, patients who receive that procedure might be a selected group, presumably at lower risk of leakage. Recording of postoperative complications in the Danish Colorectal Cancer Group database has been validated against medical records and demonstrated almost $100 \%$ accuracy. ${ }^{35}$ Nonetheless, because there are no clear standards for the recording of anastomotic leakage ${ }^{33}$ completeness and validity in the database may be imperfect. To heighten capture of leakage cases, we also included those only recorded in the Danish National Registry of Patients, increasing the number of cases by $9 \%$. Furthermore, a sensitivity analysis we restricted to those who required reoperation, to increase the validity of the outcome, did not greatly change the observed associations.

Although data in the Danish National Registry of Medicinal Products are complete, ${ }^{25}$ some limitations may exist. The registry includes no detailed information regarding adherence, and misclassification of nonadherent patients as users is possible. However, co-payment requirements and beneficial effects on serious symptoms increase the likelihood that filled prescriptions reflect actual use. Also, glucocorticoids dispensed during hospitalisation and outpatient clinic visits are not logged in the Danish National Registry of Medicinal Products. Nonetheless, stratified analyses based on discharge diagnoses did not differ materially from those of the main analysis. Finally, due to a limited number of individuals in each glucocorticoid category, we were unable to subcategorise according to dosages of glucocorticoids. Likewise, the paucity of patients using intestinal-acting glucocorticoids did not allow for exploring subcategories according to the timing of use.

Misclassification of anastomotic leakage might also influence our results if glucocorticoid users had a temporary stoma together with their primary anastomosis more often than never-users. Because a diverting stoma may reduce the clinical symptoms of leakage, underreporting among glucocorticoid users could thus bias the estimates towards the null.

Glucocorticoid users generally differ from non-users because of the diseases for which glucocorticoids are prescribed. This situation may lead to confounding by indication. Unfortunately, the Danish National Registry of Medicinal Products provides no data regarding the indication for glucocorticoids; however, we adjusted for comorbid conditions and treatments associated with their use. Unexpectedly, we observed that almost one-half of the glucocorticoid users had no record of comorbidity (CCI score $=0$ ). However, some of these patients may have been treated solely by general practitioners whose patients' files are not logged in the Danish National Registry of Patients. As a result, recording of CCI conditions from hospitalisations and outpatient visits may be incomplete. Also, we cannot exclude the possibility of some uncontrolled confounding by preoperative radiochemotherapy that was not recorded in the Danish Colorectal Cancer Database before 2009. However, standard neo-adjuvant treatment for rectal cancer with long-course radiotherapy and concomitant chemotherapy including 5 -flourouracil ${ }^{36}$ has low emetogenicity and does not commonly imply the requirement of anti-emetics such as glucocorticoids. Therefore, preoperative oncological treatment seems unlikely to explain our findings for rectal cancer. Although rarely indicated, preoperative chemotherapy for cancer in the colon may involve glucocorticoids. However, assuming that chemotherapy may increase risk of anastomotic leakage after CRC resection, lack of adjustment for this potential confounding factor would not explain our null results for colon cancer. Finally, data regarding smoking were incomplete ( $27 \%$ missing) and might suffer from under-reporting. Although we adjusted for smoking and associated diseases/medications for COPD as proxies, residual confounding may explain the apparent association between inhaled glucocorticoids and anastomotic leakage in patients with rectal cancer. Given their limited bioavailability, we would not expect a stronger association for inhaled glucocorticoids than for oral glucocorticoids. ${ }^{37}$ In conclusion, we found that preadmission glucocorticoid use increased the risk of anastomotic leakage mainly after rectal cancer resection. However, differences in absolute risk were small, and the clinical impact of glucocorticoid use may therefore be limited.

Contributors HTS, RE and EBO designed the study. EBO and AHR were responsible for acquiring the data and conducting the analysis. EBO drafted the first version of the manuscript, and all the authors contributed to the interpretation of the findings and critical revision of the draft. All the authors approved the final version of the manuscript submitted, including the authorship list.

Funding This study was supported in part by Manufacturer Einar Willumsen's Memorial Scholarship (to EBO); Dagmar Marshall's Foundation (to EBO); Director Jacob Madsen and Olga Madsen's Foundation (to EBO); Else and Mogens Wedell-Wedellborg Foundation (to EBO); the Karen Elise Jensen Foundation (to HTS); The Danish Cancer Society (R73-A4284-13-S17) (to HTS); the Aarhus University Research Foundation (DACMUC) (to HTS); and The Clinical Epidemiological Research Foundation, Aarhus University Hospital, Denmark (to EBO).

Competing interests None declared.

Ethics approval The study was approved by the Danish Data Protection Agency (record number 2011-41-6151) and the National Board of Health.

Provenance and peer review Not commissioned; externally peer reviewed. Data sharing statement No additional data are available. 
Open Access This is an Open Access article distributed in accordance with the Creative Commons Attribution Non Commercial (CC BY-NC 4.0) license, which permits others to distribute, remix, adapt, build upon this work noncommercially, and license their derivative works on different terms, provided the original work is properly cited and the use is non-commercial. See: http:// creativecommons.org/licenses/by-nc/4.0/

\section{REFERENCES}

1. Kube R, Mroczkowski P, Granowski D, et al. Anastomotic leakage after colon cancer surgery: a predictor of significant morbidity and hospital mortality, and diminished tumour-free survival. Eur J Surg Oncol 2010;36:120-4.

2. Frye J, Bokey EL, Chapuis PH, et al. Anastomotic leakage after resection of colorectal cancer generates prodigious use of hospital resources. Colorectal Dis 2009;11:917-20.

3. Mirnezami A, Mirnezami R, Chandrakumaran K, et al. Increased local recurrence and reduced survival from colorectal cancer following anastomotic leak: systematic review and meta-analysis. Ann Surg 2011;253:890-9.

4. Jacobs JWG, Bijlsma JWJ. Glucocorticoid therapy. In: Firestein GS, Budd RC, Harris ED, et al., eds. Kelly's textbook of rheumatology. 8th edn. St. Louis, MO: W.B. Saunders Company, 2008:863

5. Anstead GM. Steroids, retinoids, and wound healing. Adv Wound Care 1998;11:277-85.

6. Schacke H, Docke WD, Asadullah K. Mechanisms involved in the side effects of glucocorticoids. Pharmacol Ther 2002;96:23-43.

7. Baca B, Ozben V, Boler DE, et al. Effect of corticosteroid dose and duration of administration on colonic anastomosis. Inflamm Bowel Dis 2010;16:2162-7.

8. Furst MB, Stromberg BV, Blatchford GJ, et al. Colonic anastomoses: bursting strength after corticosteroid treatment. Dis Colon Rectum 1994;37:12-15.

9. Phillips JD, Kim CS, Fonkalsrud EW, et al. Effects of chronic corticosteroids and vitamin $A$ on the healing of intestinal anastomoses. Am J Surg 1992;163:71-7.

10. Mastboom WJ, Hendriks T, de Man BM, et al. Influence of methylprednisolone on the healing of intestinal anastomoses in rats. Br J Surg 1991;78:54-6.

11. Eubanks TR, Greenberg JJ, Dobrin PB, et al. The effects of different corticosteroids on the healing colon anastomosis and cecum in a rat model. Am Surg 1997;63:266-9.

12. Suding $P$, Jensen $E$, Abramson MA, et al. Definitive risk factors for anastomotic leaks in elective open colorectal resection. Arch Surg 2008;143:907-11; discussion 911-12.

13. Slieker JC, Komen N, Mannaerts GH, et al. Long-term and perioperative corticosteroids in anastomotic leakage: a prospective study of 259 left-sided colorectal anastomoses. Arch Surg 2012;147:447-52.

14. Konishi T, Watanabe T, Kishimoto J, et al. Risk factors for anastomotic leakage after surgery for colorectal cancer: results of prospective surveillance. J Am Coll Surg 2006;202:439-44.

15. Ziegler MA, Catto JA, Riggs TW, et al. Risk factors for anastomotic leak and mortality in diabetic patients undergoing colectomy: analysis from a statewide surgical quality collaborative. Arch Surg 2012;147:600-5.

16. Lake JP, Firoozmand E, Kang JC, et al. Effect of high-dose steroids on anastomotic complications after proctocolectomy with ileal pouch-anal anastomosis. J Gastrointest Surg 2004;8:547-51.
17. Tresallet C, Royer B, Godiris-Petit G, et al. Effect of systemic corticosteroids on elective left-sided colorectal resection with colorectal anastomosis. Am J Surg 2008;195:447-51.

18. Richards $\mathrm{CH}$, Campbell V, Ho C, et al. Smoking is a major risk factor for anastomotic leak in patients undergoing low anterio resection. Colorectal Dis 2012;14:628-33.

19. Krarup PM, Jorgensen LN, Andreasen AH, et al, Danish Colorectal Cancer Group. A nationwide study on anastomotic leakage after colonic cancer surgery. Colorectal Dis 2012;14:e661-7.

20. Frank L. Epidemiology. When an entire country is a cohort. Science 2000;287:2398-9.

21. Iversen LH. Aspects of survival from colorectal cancer in Denmark [doctoral thesis]. Aarhus: Faculty of Health Sciences, Aarhus University, 2011.

22. Danish Colorecal Cancer Group. Nationwide database of colorectal cancer: annual report 2010. Copenhagen: DCCG, 2011:103 p.

23. Daabiss M. American Society of anaesthesiologists physical status classification. Indian J Anaesth 2011;55:111-15.

24. Ostenfeld EB, Froslev T, Friis S, et al. Completeness of colon and rectal cancer staging in the Danish Cancer Registry, 2004-2009. Clin Epidemiol 2012;4(Suppl 2):33-8.

25. Kildemoes HW, Sorensen HT, Hallas J. The Danish National Prescription Registry. Scand J Public Health 2011;39(7 Suppl):38-41.

26. Johannesdottir SA, Horvath-Puho E, Dekkers OM, et al. Use of glucocorticoids and risk of venous thromboembolism: a nationwide population-based case-control study. JAMA Intern Med 2013;173:743-52

27. Lynge E, Sandegaard JL, Rebolj M. The Danish National Patient Register. Scand J Public Health 2011;39(7 Suppl):30-3.

28. Charlson ME, Pompei P, Ales KL, et al. A new method of classifying prognostic comorbidity in longitudinal studies: development and validation. J Chronic Dis 1987;40:373-83.

29. Fleiss JL, Levin BA, Paik MC. Statistical methods for rates and proportions. 3rd edn. Hoboken, NJ: J. Wiley, 2003:xxvii, 760s., ill.

30. Davis B, Rivadeneira DE. Complications of colorectal anastomoses: leaks, strictures, and bleeding. Surg Clin North Am 2013;93: 61-87.

31. Klein M, Gogenur I, Rosenberg J. Postoperative use of non-steroidal anti-inflammatory drugs in patients with anastomotic leakage requiring reoperation after colorectal resection: cohort study based on prospective data. BMJ 2012;345:e6166.

32. Eriksen TF, Lassen CB, Gogenur I. Treatment with corticosteroids and the risk of anastomotic leakage following lower gastrointestinal surgery: a literature survey. Colorectal Dis 2014;16:0154-60.

33. Rahbari NN, Weitz J, Hohenberger W, et al. Definition and grading of anastomotic leakage following anterior resection of the rectum: a proposal by the International Study Group of Rectal Cancer. Surgery 2010;147:339-51.

34. Thygesen SK, Christiansen CF, Christensen S, et al. The predictive value of ICD-10 diagnostic coding used to assess Charlson Comorbidity Index conditions in the population-based Danish National Registry of Patients. BMC Med Res Methodol 2011;11:83.

35. Nickelsen TN, Harling $\mathrm{H}$, Kronborg $\mathrm{O}$, et al. The completeness and quality of the Danish Colorectal Cancer clinical database on colorectal cancer. Ugeskr Laeger 2004;166:3092-5.

36. Danish Colorectal Cancer Group. DCCG's nationale retningslinier. http://dccg.dk/retningslinjer/indeks.html (accessed 14 May 2015).

37. Kelly HW. Comparison of inhaled corticosteroids: an update. Ann Pharmacother 2009;43:519-27. 